\title{
Neonatal Sepsis with Multi-Organ Failure and Treated with a New Dialysis Device Specifically Designed for Newborns
}

\author{
Licia Peruzzi Roberto Bonaudo Alessandro Amore Federica Chiale \\ Maria Elena Donadio Luca Vergano Rosanna Coppo \\ SC Nefrologia Dialisi e Trapianto Ospedale Infantile Regina Margherita, AO Città della \\ Salute e della Scienza, Turin, Italy
}

\section{Key Words}

Sepsis · Acute kidney injury · Newborn · Continuous renal replacement therapy

\begin{abstract}
Neonatal sepsis due to $E$. coli is often complicated by multiple organ failure (MOF) and a high mortality risk. We report the case of a term newborn discharged in good condition who suddenly fell into septic shock after 11 days and required immediate resuscitation, volume expansion and a high-dosage amine infusion. Extremely severe metabolic acidosis, disseminated intravascular coagulation (DIC) with diffuse bleeding, and unstable hemodynamic status with oliguria turned into strict anuria, and the patient became anuric. The presence of DIC, with gastric and intestinal bleeding, rendered peritoneal dialysis impossible. Continuous renal replacement therapy (CRRT) was started with the new dialysis machine CARPEDIEM ${ }^{\circledR}$ (Cardio-Renal Pediatric Dialysis Emergency Machine), available on a trial-basis in our center, after the surgical placement of jugular double-lumen central venous catheters. A 'ready to use' neonatal kit with a low-priming volume of the extracorporeal circuit allowed a prompt hemofiltration start. The filtration CRRT was continuously performed for $48 \mathrm{~h}$, then intermittently ( $12 \mathrm{~h}$ /day) for 2 more days and interrupted on day 5 for diuresis reprisal. Acute kidney injury and multi-organ failure resolved after 5 days. The child survived without neurological damage, with a normal renal function and a normal development at 9 months follow-up. In conclusion, a prompt CRRT start with this specifically designed neonatal device allowed a progressive stabilization of hemodynamics, a better control of acidosis, a reduction of amine requirement, a gradual control of fluid overload and a rapid improvement of MOF, DIC as
\end{abstract}


Peruzzi et al.: Neonatal Sepsis with Multi-Organ Failure and Treated with a New Dialysis Device Specifically Designed for Newborns

well as a resolution of the acute kidney injury. The device also allowed the extension of CRRT in the neonatal age.

(c) 2014 S. Karger AG, Basel

\section{Introduction}

Late-onset neonatal sepsis due to $E$. coli infection is a life-threatening condition that frequently progresses to multiple organ failure (MOF) and carries a high mortality risk [1]. Recent data report unfavorable outcomes in almost $50 \%$ of affected children [1-3].

The milestone of septic shock treatment is fluid expansion [4]; however, this is frequently limited by a decrease in urinary output. Oligoanuria leads to a rapid fluid overload, which is a well-known negative prognostic factor for survival, especially when exceeding $25 \%$ of the initial body weight [5]. Sepsis is associated with the release of inflammatory cytokines and vasoactive factors, leading to endothelial damage with cardiac activity depression and an induction of multisystem organ failure [6].

Here we describe the case of a male newborn, admitted in July 2013 for septic shock due to E. coli on the 11th day of his life. He rapidly developed MOF with anuric acute kidney injury (AKI). The child could not be treated with peritoneal dialysis due to his severe intestinal bleeding. He had a favorable outcome after a prompt and successful treatment with continuous renal replacement therapy (CRRT), with a new dialysis device specifically designed for neonatal use.

\section{Case Report}

A male newborn was operatively delivered at the term of a physiologic pregnancy after a 24-hour premature rupture of his membranes in July 2013. His birth weight was 3,710 g and his Apgar score was 2/10/10. Maternal vaginal cultures, including Streptococcus Agalactiae and E. coli, were negative. He was discharged in good condition after 3 days.

After 10 days of breast-feeding, he suffered from diarrhea, and on the subsequent day, lethargy and refusal to eat developed. Within a few hours, he developed a diffuse cyanosis, hypotonia and areflexia; he was then immediately transported to the intensive care unit of our hospital.

On admittance, his general condition was extremely critical (shock, severe bradycardia, bradypnea, diffuse cyanosis and an oxygen saturation of $80 \%$ under a positive pressure mask), which made a pressure mask necessary. In poor condition but still with present reactivity, the resuscitation procedures were started immediately.

His first lab results showed severe metabolic acidosis $\left[\left(\mathrm{pH} 6.9, \mathrm{HCO}_{3^{-}} 3 \mathrm{mEq} / \mathrm{l}\right.\right.$, base excess of -22 and lactic acid of $17 \mathrm{mmol} / \mathrm{l}$ (normal value $<2 \mathrm{mmol} / \mathrm{l}$ )], hypoglycemia (blood glucose $5 \mathrm{mg} / \mathrm{dl}$ ), and a slightly increased C-reactive protein value (CRP: $15 \mathrm{mg} / \mathrm{l}$, normal value $<5 \mathrm{mg} / \mathrm{l}$ ). Disseminated intravascular coagulation (DIC) was detected: fibrinogen 41 $\mathrm{mg} / \mathrm{dl}$, D-dimer $29.8 \mathrm{mg} / \mathrm{l}$ (normal value $<2 \mathrm{mg} / \mathrm{l}$ ) and thrombocytopenia $(37,000$ platelets $/ \mu \mathrm{l}$ ), with hemorrhagic skin lesions and gastric, enteric and bronchial bleeding. The child was dehydrated, with a hemoglobin level of $21 \mathrm{~g} / \mathrm{dl}$ and his hematocrit at $62 \%$.

Immediate resuscitation included nasotracheal ventilation, intra-osseous norepinephrine due to the impossibility of placing a venous line, a volume expansion with saline, human albumin, bicarbonate and fresh frozen plasma. Antibiotic treatment with meropenem and vancomycin was started. Platelets and coagulation factors were infused due to his profuse bleeding. 
Peruzzi et al:: Neonatal Sepsis with Multi-Organ Failure and Treated with a New Dialysis Device Specifically Designed for Newborns

The child showed extreme hemodynamic instability (with bursts of his paroxysmal supraventricular tachycardia (heart rate $>250$ beats $/ \mathrm{min}$ ) alternate to bradycardia (heart rate $<70$ beats/min), extreme hypotension (invasive mean blood pressure 40/25 mm Hg) requiring norepinephrine and then epinephrine at high dosage $(1 \mu \mathrm{g} / \mathrm{kg} / \mathrm{min})$.

He rapidly developed oligoanuria and was not responsive to furosemide. He then received strict anuria within $24 \mathrm{~h}$. He had persistent severe acidosis and a hemodynamic instability with high-dose inotropic requirement, impaired gas exchange (although highpressure nasotracheal mechanical ventilation was intact), a positive fluid balance ( $>560 \mathrm{ml}$; $>25 \%$ fluid overload) and a positive hemoculture for E. coli (table 1).

Nephrological consultation defined a situation of anuric AKI secondary to septic shock and MOF and therefore indicating CRRT. Peritoneal dialysis was excluded due to an absolute contraindication presented by gastro-intestinal diffuse bleeding and abdominal hypoperfusion with a high risk of bowel perforation.

A double-lumen central venous catheter for dialysis (diameter $5 \mathrm{~F}$, length $6 \mathrm{~cm}$ ) was surgically placed in the internal jugular vein due to the impossibility of being able to use his femoral veins (bleeding and large hematomas). Subnecrotic peripheral lesions on his feet were also detected.

Continuous venovenous hemofiltration was started with the new neonatal device CARPEDIEM $^{\circledR}$ (Cardio-Renal Pediatric Dialysis Emergency Machine, Bellco, Mirandola, Italy), available in our center on a trial-basis. The neonatal dialysis kit used included a $0.25-\mathrm{m}^{2}$ dialyzer in medisulphone polysulphone, with a suggested priming of $19 \mathrm{ml}$ for the filter, and $41 \mathrm{ml}$ for the complete circuit. Due to the patient's bleeding status at the start of treatment (international normalized ratio 9; activated clotting time $400 \mathrm{~s}$; platelets 20,000/ $\mathrm{ll}$; table 1), the circuit was then rinsed without heparin, and no anticoagulant was required during treatment. The dialysis parameters were blood flow (Qb) $26 \mathrm{ml} / \mathrm{min}$, net weight loss 40 $\mathrm{ml} / \mathrm{h}$, reinfusion (QRf) in post dilution $255 \mathrm{ml} / \mathrm{h}$, maximal for this dialysis machine, specifically designed for acute renal injury treatment after cardiac surgery in the neonatal age [7].

Central venous pressure was assessed with an indwelling central venous catheter in the right atrium, connected with a transducer, which was $9 \mathrm{cmH}_{2} \mathrm{O}$ at the beginning of CRRT.

During the first $8 \mathrm{~h}$, the clinical situation was extremely critical. The patient required high-pressure ventilation because of fluid overload, high dosages of norepinephrine and epinephrine $(1 \mu \mathrm{g} / \mathrm{kg} / \mathrm{min}$ of both drugs) for persistent hypotension, and hemodynamic instability (tachycardia bursts, unstable blood pressure with frequent drops below 60/40 $\mathrm{mm} \mathrm{Hg}$ ), unsatisfactory control of acidosis and lactic acid, which remained persistently above $8 \mathrm{mmol} / \mathrm{l}$ (normal value $<2 \mathrm{mmol} / \mathrm{l}$ ).

Net improvement of the patient's hemodynamic condition, the resolution of the tachycardia burst, a rapid improvement of his acidosis as well as a decrease of the lactic acid were observed after the substitution of the reinfusion fluid HFP32 ${ }^{\circledR}$ (Bellco, Italy), containing lactate $(32 \mathrm{mmol} / \mathrm{l})$ as a buffer with Prismasol $2^{\circledR}$ (Gambro, Sweden), containing as buffers bicarbonate (32 mmol/l) and lactate (3 mmol/l) (table 2). The improvement observed with this reinfusion fluid was attributed to a better control of acidosis due to higher bicarbonate delivery and a lower lactate burden, which could not be metabolized by the liver, which had been compromised by shock.

During the first 2 days of treatment, continuous plasma infusions and repeated platelet transfusions were required due to the DIC persistence (international normalized ratio 4.5; activated clotting time $256 \mathrm{~s}$; platelets 5,000-18,000/ $\mathrm{\mu l}$; fibrinogen $50 \mathrm{mg} / \mathrm{dl}$ ). 
The treatment was continued for $48 \mathrm{~h}$, with a change of circuit and dialyzer after $12 \mathrm{~h}$, as indicated by the machine's instructions upon reaching the maximal allowed ultrafiltration rate of $500 \mathrm{ml}$ allowed per session in the former software.

In the following 3 days, treatment was intermittent for $12 \mathrm{~h} /$ day. Progressive improvement of bleeding parameters, his hepatic function (increased coagulation factors, albumin and cholinesterase synthesis) and general condition allowed the progressive tapering of inotropic drugs as well as plasma and platelet infusions (table 1).

Diuresis reprisal occurred after 4 days, and diuresis normalization, allowing a treatment interruption, after 5 days. During the 5 days of treatment, no anticoagulation was required and no bleeding events occurred; no evidence of any central nervous system damage was visible on ultrasound and electroencephalography.

After 10 days, the patient was released from the intensive care unit. His renal function normalized within 15 days even though his kidneys remained hyperechogenic. At day 60, his neurological condition was almost normal.

At 9 months follow-up, the child had a normal neurological development without any clinical, ultrasonic and electroencephalographic abnormalities; he also showed normal growth and development. His blood pressure and renal function were normal (serum creatinine $0.36 \mathrm{mg} / \mathrm{dl}$ ) without any urinary abnormalities (including tubular proteinuria). The renal ultrasound displayed normal kidneys with normal diameters for his age $(5.8 \mathrm{~cm})$.

\section{Discussion}

Late-onset gram-negative sepsis occurring in newborns and displaying a fulminant evolution toward rapid MOF has a very poor prognosis and a high mortality rate in spite of immediate resuscitation and specialized intensive care teams [8-12].

Rapid interventions with continuous renal replacement therapy allow the control of fluid overloads, and the rapid removal of toxins and inflammatory products has dramatically improved the survival of children in AKI, particularly in those with septic shock, therefore allowing a rapid stabilization of their hemodynamic condition and a better control of fluids $[13,14]$. However, in newborns, the technical limitations (lack of approved dialysis machines and devices specifically designed for low or very low weights), frequently limits the possibility of a widespread use of this intensive approach. This fact allows treatment only in experienced and specialized pediatric nephrology centers, with the use of custom off-label adapted machinery and circuits $[15,16]$.

In this case of late-onset E. coli sepsis that rapidly evolved to severe MOF, intensive volume expansion, inotropic and respiratory support were not sufficient to avoid the rapid worsening of the patient's kidney functions to anuric AKI (as well as liver and cardiac failure). Moreover, the patient had severe intestinal bleeding due to DIC, which rendered peritoneal dialysis impossible. The availability of CRRT in our center, with a new machine specifically designed for the newborn, allowed the start of treatment within $24 \mathrm{~h}$ and therefore led to a rapid improvement of his hemodynamic parameters as well as an efficient treatment of fluid overload. This dialysis machine was specifically developed in Vicenza (Italy) [(as detailed in 7)] for the treatment of newborns and small infants (weight range of 2-9 kg). The device was available on a trial basis in our center in July 2013 and chosen for this patient because of its peculiar technical characteristics.

The main technical novelties of the CARPEDIEM ${ }^{\circledR}$ device is the fact that it provides an extremely precise control over fluid infusion and the ultrafiltration through peristaltic pumps, driven by 2 scales with a resolution of $1 \mathrm{~g}$, allowing a precision of $1 \mathrm{ml} / \mathrm{min}$ 
reinfusion and an ultrafiltration accuracy within the limit of $1 \mathrm{~g} / \mathrm{h}$. The miniaturized circuit and dialyzer require an extremely low extracorporeal blood volume $(41 \mathrm{ml}$ in total for the circuit equipped with the $0.25 \mathrm{~m}^{2}$ dialyzer) and the possibility to use an extremely reduced blood flow (starting at a $\mathrm{Qb}$ of $2 \mathrm{ml} / \mathrm{min}$ ), allowing an easier and safer use in hemodynamically unstable and critical small infants.

The prompt treatment of our patient through CRRT allowed a rapid and uneventful removal of fluid overload as well as of sepsis-associated cytokines. The treatment was not associated with any additive bleeding or hemodynamic risks and allowed a better acid base and electrolytic control, with a rapid stabilization of his hemodynamic parameters. The extremely low extracorporeal prime volume also allowed good control of the boy's body temperature without any need for supplementary warming devices and with an avoidance of blood priming in the circuit. The possibility to promptly reduce fluid overload through an extremely precise control of ultrafiltration contributes to a more efficient treatment of critically ill newborns (as septic shock), allowing a proper plasma, calorie and therapy supply and a less stressful ventilatory support with a better outcome and survival rate.

AKI itself represents an independent risk factor for mortality and morbidity in children, with a significant odds ratio in all settings, variable between 2 and 14 [17], particularly when associated with sepsis and anuria, and with a fluid overload above $25 \%[5,18,19]$.

Moreover, sepsis itself induces a cascade of cytokines, a release of vasoactive and cytotoxic factors with rapid multiple organ damage, which can only be interrupted by efficient dialytic removal, with outcomes proportional to an early start [14].

While this concept is well established in the intensive care of adults, in neonatal care, due to a lack of specific devices, the technical difficulties have so far delayed the diffusion of this approach.

The availability of a ready-to-use extracorporeal circuit with an easy dialysis machine, with precise ultrafiltration control specifically designed for newborns, can extend the diffusion of this therapeutic option, not only to expert pediatric nephrologists, but also to intensive care neonatology units, providing a prompt treatment of sepsis and fluid overload and therefore a better survival rate for our patients.

\section{Acknowledgements}

The technical help of Dr. Eng. Roberto Cena (R\&D Marketing Department, Bellco) and of Dr. Mary Lou Wratten (Chief Scientific Officer, Bellco) is greatly acknowledged. The patient's family approved and authorized the analysis of the clinical data.

\section{Disclosure Statement}

The authors declare no conflict of interest. No funding was obtained for this study. All authors have no financial interests in this paper.

\section{References}

1 Stoll BJ, Hansen NI, Sánchez PJ, et al: Early onset neonatal sepsis: the burden of group B Streptococcal and E. coli disease continues. Pediatrics 2011;127:817-826.

2 Weston EJ, Pondo T, Lewis MM, et al: The burden of invasive early-onset neonatal sepsis in the United States, 2005-2008. Pediatr Infect Dis J 2011;30:937-941. 


\begin{tabular}{l|l}
\hline Case Rep Nephrol Urol 2014;4:113-119 \\
\hline DOI: 10.1159/000363691 & $\begin{array}{l}\text { C 2014 S. Karger AG, Basel } \\
\text { www.karger.com/cru }\end{array}$ \\
\hline
\end{tabular}

Peruzzi et al.: Neonatal Sepsis with Multi-Organ Failure and Treated with a New Dialysis Device Specifically Designed for Newborns

3 Brocklehurst P, Farrell B, King A, et al: Treatment of neonatal sepsis with intravenous immune globulin. $\mathrm{N}$ Engl J Med 2011;365:1201-1211.

-4 Dellinger RP, Carlet JM, Masur H, et al: Surviving Sepsis Campaign guidelines for management of severe sepsis and septic shock. Crit Care Med 2004;32:858-873.

-5 Sutherland SM, Zappitelli M, Alexander SR, et al: Fluid Overload and mortality in children receiving continuous renal replacement therapy: the prospective pediatric continuous renal replacement therapy registry. Am J Kidney Dis 2010;55:316-325.

6 Angus DC, van der Poll T: Severe sepsis and septic shock. N Engl J Med 2013;369:840-851.

7 Ronco C, Garzotto F, Ricci Z: CA.R.PE.DI.E.M. (Cardio-Renal Pediatric Dialysis Emergency Machine): evolution of continuous renal replacement therapies in infants. A personal journey. Pediatr Nephrol 2012;27:1203-1211.

-8 Ozkan H, Cetinkaya M, Koksal N, et al: Culture-proven neonatal sepsis in preterm infants in a neonatal intensive care unit over a 7-year period: coagulase-negative Staphylococcus as the predominant pathogen. Pediatr Int 2014;56:60-66.

-9 Mukhopadhyay S, Puopolo KM: Risk assessment in neonatal early onset sepsis. Semin Perinatol 2012;36:408-415.

10 Camacho-Gonzalez A, Spearman PW, Stoll BJ: Neonatal infectious diseases: evaluation of neonatal sepsis. Pediatr Clin North Am 2013;60:367-389.

11 Tsai CH, Chen YY, Wang KG, et al: Characteristics of early-onset neonatal sepsis caused by Escherichia coli. Taiwan J Obstet Gynecol 2012;51:26-30.

-12 Jones B, Peake K, Morris AJ, et al: Escherichia coli: a growing problem in early onset neonatal sepsis. Aust N Z J Obstet Gynaecol 2004;44:558-561.

13 Dellinger RP, Levy MM, Rhodes A, et al: Surviving Sepsis Campaign: international guidelines for management of severe sepsis and septic shock, 2012. Intensive Care Med 2013;39:165-228.

14 Honoré PM, Matson JR: Hemofiltration, adsorption, sieving and the challenge of sepsis therapy design. Crit Care 2002;6:394-396.

15 Sutherland SM, Alexander SR: Continuous renal replacement therapy in children. Pediatr Nephrol 2012;27:2007-2016.

16 Askenazi DJ, Goldstein SL, Koralkar R, et al: Continuous renal replacement therapy for children $\leq 10 \mathrm{~kg}$ : a report from the prospective pediatric continuous renal replacement therapy registry. J Pediatr 2013;162:587-592.e3.

-17 Alkandari O, Eddington KA, Hyder A, et al: Acute kidney injury is an independent risk factor for pediatric intensive care unit mortality, longer length of stay and prolonged mechanical ventilation in critically ill children: a two-center retrospective cohort study. Crit Care 2011;15:R146.

$\checkmark 18$ Askenazi DJ, Koralkar R, Hundley HE, et al: Fluid overload and mortality are associated with acute kidney injury in sick near-term/term neonate. Pediatr Nephrol 2013;28:661-666.

19 Godin M, Bouchard J, Mehta RL: Fluid balance in patients with acute kidney injury: emerging concepts. Nephron Clin Pract 2013;123:238-245. 


\begin{tabular}{l|l}
\hline DOI: 10.1159/000363691 & $\begin{array}{l}\text { ○ 2014 S. Karger AG, Basel } \\
\text { www.karger.com/cru }\end{array}$ \\
\hline
\end{tabular}

Peruzzi et al.: Neonatal Sepsis with Multi-Organ Failure and Treated with a New Dialysis Device Specifically Designed for Newborns

Table 1. Main laboratory and clinical parameters during CRRT

\begin{tabular}{|c|c|c|c|c|}
\hline & CRRT start & $24 \mathrm{~h}$ & $48 \mathrm{~h}$ & 5 days \\
\hline $\mathrm{Na}^{+}, \mathrm{mEq} / \mathrm{l}$ & 139 & 136 & 136 & 137 \\
\hline $\mathrm{K}^{+}, \mathrm{mEq} / \mathrm{l}$ & 4.5 & 2.8 & 3.1 & 2.7 \\
\hline $\mathrm{Ca}^{++}, \mathrm{mEq} / \mathrm{l}$ & 2.5 & 2.75 & 2.75 & 2.6 \\
\hline $\mathrm{HCO}_{3}^{-}$ & 17 & 22 & 24.2 & 25.1 \\
\hline Base excess & -9.3 & -2.7 & -0.6 & 0.7 \\
\hline $\mathrm{pH}$ & 7.1 & 7.3 & 7.36 & 7.38 \\
\hline Lactate, $\mathrm{mmol} / \mathrm{l}(\mathrm{nv}<2 \mathrm{mmol} / \mathrm{l})$ & 13 & 7.5 & 4 & 1.3 \\
\hline Serum creatinine, $\mathrm{mg} / \mathrm{dl}$ (IDMS nv $<0.3 \mathrm{mg} / \mathrm{dl}$ ) & 1.22 & 0.67 & 0.56 & 0.88 \\
\hline Diuresis, $\mathrm{ml} / \mathrm{kg} / \mathrm{h}$ & 0 & 0 & 0 & $2 \rightarrow 3$ \\
\hline AST, IU/ml & 4,500 & 605 & 128 & 166 \\
\hline ALT, IU/ml & 1,116 & 611 & 307 & 133 \\
\hline Bilirubin, mg/dl (nv <1.5 mg/dl) & 8 & 6.7 & 14.2 & 12.2 \\
\hline C-reactive protein, $\mathrm{mg} / \mathrm{l} /(\mathrm{nv}<5 \mathrm{mg} / \mathrm{l})$ & 65 & 59 & 66 & 35 \\
\hline Procalcitonin, $\mathrm{ng} / \mathrm{ml}(\mathrm{nv}<0.5 \mathrm{ng} / \mathrm{ml})$ & 188 & 92 & 46 & 19 \\
\hline Hemoglobin, g/dl & 7.7 & 10.9 & 9.5 & 10.8 \\
\hline Platelets/ $\mu \mathrm{l}$ & 8,000 & 5,000 & 10,000 & 29,000 \\
\hline INR & 4 & 1.87 & 2.08 & 1.66 \\
\hline PTT, s & 81 & 52.9 & 56.4 & 50 \\
\hline ATC, s (nv <40 s) & 256 & 210 & 180 & 170 \\
\hline Hemoculture & Pos E.coli & & & \\
\hline Central venous pressure, $\mathrm{cm} \mathrm{H}_{2} \mathrm{O}$ & 9 & 6 & 3 & 3 \\
\hline \multicolumn{5}{|l|}{ Inotropic drugs } \\
\hline Epinephrine $/$ norepinephrine, $\mu \mathrm{g} / \mathrm{kg} / \mathrm{min}$ & 1 & 0.2 & 0.1 & stop \\
\hline
\end{tabular}

$\mathrm{nv}=$ Normal value; $\mathrm{INR}=$ international normalized ratio; $\mathrm{PTT}=$ partial thromboplastin AST $=$ aspartate aminotransferase; $\mathrm{ALT}$ = alanine aminotransferase; IDMS = isotope dilution mass spectrometry-traceable creatinine; ATC = activated clotting time.

Table 2. Composition of adopted reinfusion solutions

\begin{tabular}{lll}
\hline Component in mmol/l & HPF32 & Prismasol \\
\hline $\mathrm{Na}^{+}$ & 140 & 140 \\
$\mathrm{~K}^{+}$ & 2 & 2 \\
$\mathrm{Ca}^{++}$ & 1.5 & 1.75 \\
$\mathrm{Mg}^{++}$ & 0.5 & 0.5 \\
$\mathrm{Cl}^{-}$ & 114 & 111.5 \\
Lactate & 32 & 3 \\
Glucose & 5.5 & 6.1 \\
Bicarbonate & 0 & 32 \\
\hline
\end{tabular}

